\title{
Penambahan Kayu Manis Dan Gula Merah Terhadap Kadar Vitamin C Dan Ic 50 Dalam Jus Jambu Biji Merah
}

\section{Addition of Cinnamon and Brown Sugar on Vitamin C and IC $C_{50}$ Levels in Red Guava Juice}

\author{
Anak Agung Ngurah Dwi Ariesta Wijaya Putra ${ }^{1)}$ dan Putu Rima Sintyadewi ${ }^{1)}$ \\ ${ }^{1)}$ Institut Teknologi dan Kesehatan Bali \\ Kampus II: Jalan Tukad Balian No. 180, Renon, Denpasar, Bali
}

Korespondensi Penulis: ariestawijayaputra.work@gmail.com

\begin{abstract}
Indonesia as a tropical country has various kinds of fruit varieties. One of the famous fruits in Indonesia is guava. Guava fruit is popular with the public because it has a sweet taste. Ripe guava flesh can be processed into processed products such as jelly, jam, guava flour, fruit salad, fruit soup, chips, fruit juice, and fresh drinks. The benefits of guava fruit are many, such as being able to overcome several types of diseases such as diabetes, hypertension, and cancer. In addition, guava is also useful as an anti-bacterial, anti-fungal, anti-inflammatory, and can maintain skin health. Guava contains various vitamins and antioxidants that are beneficial for the body. The purpose of this study was to determine the content of vitamin $\mathrm{C}$ and antioxidant activity in guava juice added with cinnamon and brown sugar. This test uses 8 combinations of brown sugar and cinnamon treatments. The results showed that the best vitamin $\mathrm{C}$ content and antioxidant activity were found in the K2G0 treatment (4\% cinnamon and $0 \%$ brown sugar) with a vitamin $\mathrm{C}$ content of 57,15 $\mathrm{mg} / 100 \mathrm{~g}$ and an $\mathrm{IC}_{50}$ value of $39,08 \mathrm{ppm}$.
\end{abstract}

Keywords: brown sugar, cinnamon, guava, vitamin c, antioxidant activity

\section{PENDAHULUAN}

Jambu biji memiliki nama latin Psidium guajava. Psidium dari bahasa Yunani Kuno yang berarti delima, sedangkan guajava diadaptasi dari bahasa Spanyol yaitu Guabaya yang merupakan sebutan untuk pohon jambu biji (Morton, 1987).

Jambu biji mengandung berbagai macam vitamin dan mineral yang berguna bagi tubuh. Buahnya yang matang biasanya dimakan segar sebagai buah meja atau dipakai sari buah. Disamping itu, daging buah jambu biji yang sudah matang dapat diproses menjadi produk olahan seperti jeli, selai, tepung jambu biji, salad buah, sop buah, keripik, sari buah, dan minuman segar. Jambu biji merah mengandung senyawa fitonutrien sebagai antioksidan diantaranya vitamin $\mathrm{C}$, vitamin
E, Vitamin A, selenium, zinc, asam elagik, lignin antocyanidin dan fenol flavonoid (Wiralis, 2009).Uzzaman et al. (2018) menyatakan bahwa jambu biji bermanfaat mampu mengatasi beberapa jenis penyakit seperti diabetes, hipertensi, dan kanker. Selain itu jambu biji juga bermanfaat sebagai anti-bakteri, anti-jamur, anti-inflamasi, serta dapat menjaga kesehatan kulit.

Kayu manis (Cinnamomum burmannii) memiliki aroma khas sehingga sering digunakan sebagai bahan penyeda makanan (Abdurachman dan Hadjib, 2011). Kayu manis juga memiliki rasa manis dan pedas sehingga cocok untuk dijadikan bahan tambahan pada minuman seperti sirup (Ferry, 2013). 
Gula merah adalah gula yang berbahan baku air nira dari pohon kelapa (Cocos nucifera Linn.). Memiliki bentuk padat dengan warna yang coklat kemerahan hingga coklat tua. Gula merah memiliki banyak kegunaan selain sebagai pemanis makanan juga digunakan sebagai penyedap masakan, campuran dalam pembuatan cuka untuk empekempek, kecap dan minuman (Kristianingrum, 2009).

Penelitian ini dilakukan untuk mengetahui kadar vitamin $\mathrm{C}$ dan aktivitas antioksidan pada sari buah jambu biji merah dengan penambahan kayu manis dan gula merah.

\section{METODE PENELITIAN}

Penelitian ini dilaksanakan di Laboratorium Ilmu - Ilmu Dasar, Fakultas Pertanian, Universitas Warmadewa, pada bulan November 2020.

Bahan yang digunakan pada penelitian ini adalah buah jambu biji merah,air mineral, gula merah, bubuk kayu manis, aquades, amilum, $\mathrm{NaOH}, \mathrm{DPPH}$ (1,1 diphenil-2-pikrihidrazil), BHT (Butil Hidroksi Toluen) dan iodin. Instrumen peralatan yang digunakan adalah blender, pisau, kain saring, kompor, panci, buret, pipet tetes, gelas beker, erlenmeyer, dan spatula.

Perlakuan dalam penelitian ini adalah perbandingan antara kayu manis dan gula dalam pembuatan jus jambu biji merah (Tabel 1). Data yang diperoleh dianalisis menggunakan uji sidik ragam satu faktor (One-Way Anova) pada nilai $\alpha=$ $5 \%$. Program yang digunakan adalah JASP (Jeffreys's Amazing Statistics Program)

\section{Tabel 1. Perlakuan}

\begin{tabular}{ccc}
\hline No. & $\begin{array}{c}\text { Kode } \\
\text { sampel }\end{array}$ & $\begin{array}{c}\text { Kayu Manis : Gula } \\
\text { Merah }\end{array}$ \\
\hline 1 & K1G0 & $2 \%: 0 \%$ \\
2 & K1G1 & $2 \%: 3 \%$ \\
3 & K1G2 & $2 \%: 6 \%$ \\
4 & K1G3 & $2 \%: 9 \%$ \\
5 & K2G0 & $4 \%: 0 \%$ \\
6 & K2G1 & $4 \%: 3 \%$ \\
7 & K2G2 & $4 \%: 6 \%$ \\
8 & K2G3 & $4 \%: 9 \%$ \\
\hline
\end{tabular}

\section{Pembuatan Sari Buah}

\section{Sortasi}

Bertujuan untuk mendapatkan bahan baku yang berkualitas baik sehingga akan didapatkan hasil akhir yang memiliki kriteria sari buah jambu yang baik pula. Sortasi dapat dilakukan secara manual untuk memilih jambu yang berkualitas bagus. Kriteria jambu yang baik antara lain :Tua optimal, Tidak mengalami kerusakan biologis, mikrobiologis maupun kimiawi

\section{Penimbangan}

Penimbangan dilakukan untuk mendapatkan formula yang tepat dalam menghasilkan produk akhir yang baik.

\section{Pencucian}

Memiliki tujuan untuk membersihkan sisa kotoran pasca panen yang mungkin masih melekat pada bahan baku jambu. Pencucian dilakukan dengan menggunakan air bersih yang mengalir hingga bahan bersih dari kotoran yang ada.

\section{Pengupasan}

Pengupasan bertujuan untuk memisahkan antara daging buah dari kulit buah, hal ini dilakukan agar warna dari produk yang dihasilkan sesuai dengan warna jambu biji itu sendiri. 


\section{Pengecilan ukuran}

Pengecilan ukuran dilakukan dengan menggunakan pisau dengan tujuan untuk memperkecil ukuran jambu sehingga akan mempermudah dan mempercepat proses penghancuran jambu.

\section{Pemisahan biji jambu}

Pemisahan biji jambu dari daging buah bertujuan agar pada saat penghancuran biji jambu tidak ikut hancur, karena akan menimbulkan endapan pada sari buah jambu.

\section{Penghancuran}

Dilakukan dengan penambahan air matang sebanyak 3 liter air tiap $1 \mathrm{~kg}$ bahan baku yang digunakan. Penghancuran bertujuan untuk mengekstraksi jambu dan melarutkannya pada air.

\section{Penyaringan I}

Bertujuan untuk memisahkan antara sari buah yang terlarut dengan komponen-komponen lain seperti biji jambu dan kulit nya. Setelah dilakukan proses penyaringan, akan didapatkan 2 produk, yaitu sari buah jambu dan ampas. Penyaringan dapat dilakukan dengan menggunakan saringan plastik maupun dengan menggunakan kain saring yang sebelumnya telah di sterilisasi.

\section{Pasteurisasi}

Sari buah jambu yang didapat kemudian di pasteurisasi hingga suhu mencapai $65-80^{\circ} \mathrm{C}$ selama 15 menit. Tujuan dari proses ini adalah untuk menghambat pertumbuhan mikroorganisme dan mencegah aktivitas enzim. Dalam proses pasteurisasi, sari buah ditambahkan kayu manis dan gula merah sesuai perlakuan. Setelah pasteurisasi selesai, dapat dilakukan penyaringan ke 2 untuk memastikan sari buah bersih dari partikel asing yang terikut dalam gula.

\section{Penyaringan II}

Penyaringan ke 2 bertujuan untuk menyaring sari buah agar diperoleh sari buah yang bersih terbebas dari kotoran yang terikut dalam gula.

\section{Pengujian Vitamin C}

Pengujian vitamin $\mathrm{C}$ dilakukan berdasarkan metode yang dilakukan oleh Harefa, et al (2020), analisis vitamin $\mathrm{C}$ dilakukan dengan cara iodimetri, yaitu titrasi dengan iodin hingga terjadi perubahan warna. Kemudian diukur kadar vitamin $\mathrm{C}$ dengan rumus :

$$
m g \text { VitaminC }=\frac{m l \text { titrasi } x 0,88 \times P}{\text { sampd }(\mathrm{mg})}
$$

$\mathrm{P}=$ Pengenceran

$1 \mathrm{ml}$ iodium $0,01 \mathrm{~N}=0,88 \mathrm{mg}$ asam askorbat

\section{Pengujian Aktivitas Antioksidan}

Pengujian aktivitas antioksidan dilakukan berdasarkan metode yang dilakukan oleh (Amarowicz, et al (2000).

\section{Pembuatan larutan BHT 200 ppm}

Sebanyak 0,002 g BHT dimasukkan dalam labu ukur $10 \mathrm{ml}$, kemudian ditambah denganmetanol sampai garis tera.

\section{Pembuatan larutan DPPH 0,1 mM}

Sebanyak 0,001 g DPPH dimasukkan ke dalam labu ukur $10 \mathrm{ml}$, kemudian ditambahdengan metanol sampai garis tera.

\section{Pengujian Aktivitas Antioksidan}

Masing-masing konsentrasi ekstrak diambil 0,5 ml dan ditambah $1 \mathrm{ml}$ DPPH 0,1 mM. Dilakukan penambahan $4 \mathrm{ml}$ metanol, divortex sampai homogen, kemudian diinkubasi selama 30 menit. Selanjutnya dilakukan peneraan pada panjang gelombang $517 \mathrm{~nm}$.

Rumus penghitungan aktivitas antioksidan :

\%penangkapan radikal $=$ 


$$
\frac{A 1-A 2}{A 1} \times 100 \%
$$

Keterangan :

A1 = Absorbansi Kontrol

A2 = Absorbansi Sampel

Aktivitas antioksidan dapat dilihat dari nilai $\mathrm{IC}_{50}$ yaitu konsentrasi larutan sampel yang memberikan inhibisi (penghambatan) sebesar 50\% terhadap radikal DPPH. Nilai $\mathrm{IC}_{50}$ diperoleh dari persamaan regresi :

$$
Y=a+b x
$$

Dimana :

$\mathrm{Y}=\%$ inhibisi

$\mathrm{X}=$ konsentrasi larutan sampel

\section{HASIL DAN PEMBAHASAN}

\section{Kandungan Vitamin $\mathbf{C}$}

Pengujian vitamin $\mathrm{C}$ pada penelitian ini menggunakan 8 jenis perlakuan dengan tiga kali ulangan. Hasil kadar vitamin $\mathrm{C}$ dapat dilihat pada Tabel 2.

Tabel 2. Kandungan Vitamin C Jus Jambu Biji Merah

\begin{tabular}{ccc}
\hline No. & Perlakuan & Vitamin C $(\mathrm{g} / 100 \mathrm{~g})$ \\
\hline 1 & K1G0 & 51.11 \\
2 & K1G1 & 49.71 \\
3 & K1G2 & 47.41 \\
4 & K1G3 & 41.34 \\
5 & K2G0 & 57.15 \\
6 & K2G1 & 56.11 \\
7 & K2G2 & 54.47 \\
8 & K2G3 & 53.04 \\
\hline
\end{tabular}

Hasil yang ditunjukan pada Tabel 2, menyatakan bahwa kadar vitamin $\mathrm{C}$ tertinggi terdapat pada perlakuan K2G0 (4\% kayu manis dan $0 \%$ gula merah) dengan kadar sebesar 57,15 $\mathrm{mg} / 100 \mathrm{~g}$. Sedangkan kadar terendah terdapat pada perlakuan K1G3 (2\% kayu manis dan 9\% gula merah) dengan kadar sebesar 41,34 mg/100g. Data yang telah diperoleh pada Tabel 2 kemudian dilakukan uji Anova. Hasil uji Anova menunjukkan bahwa hasil analisis vitamin $\mathrm{C}$ dari 24 sampel berbeda nyata karena nilai $\mathrm{p}<0,05$ (Tabel 3).

Tabel 3. Uji Anova Kandungan Vitamin C

\begin{tabular}{rrrrrr}
\hline Cases & Sum of Squares & $d f$ & Mean Square & $F$ & $p$ \\
\hline Perlakuan & 561,948 & 7 & 80,278 & 692,278 & $<0,001$ \\
Residuals & 1,855 & 16 & 0,116 & & \\
\hline
\end{tabular}

Note. Type III Sum of Squares

Vitamin C, juga dikenal sebagai asam Laskorbat, adalah vitamin yang larut dalam air yang secara alami ada dalam beberapa makanan, ditambahkan ke makanan lain, dan tersedia sebagai suplemen makanan. Manusia, tidak seperti kebanyakan hewan, tidak dapat mensintesis vitamin $\mathrm{C}$ secara endogen, sehingga merupakan komponen makanan yang penting. Didalam tubuh, vitamin $\mathrm{C}$ bertindak sebagai antioksidan, membantu melindungi sel dari kerusakan yang 
disebabkan oleh radikal bebas (Li dan Schellhorn, 2007). Radikal bebas adalah senyawa yang terbentuk ketika tubuh kita mengubah makanan yang kita makan menjadi energi. Orang juga terpapar radikal bebas di lingkungan dari asap rokok, polusi udara, dan sinar ultraviolet dari matahari (Office of Dietary Supplements - Vitamin C, n.d.)

Kebutuhan vitamin $\mathrm{C}$ tiap orang berbeda. Hal ini dipengaruhi oleh jenis kelamin dan usia. Disamping itu, untuk ibu hamil dan ibu menyusui juga membutuhkan asupan vitamin $\mathrm{C}$ yang berbeda.

Tabel 4. Kebutuhan Asupan Vitamin C

\begin{tabular}{cc}
\hline Tahap Kehidupan & Jumlah yang direkomendasikan \\
\hline Bayi 0 - 6 bulan & $40 \mathrm{Mg}$ \\
Bayi 7 - 12 bulan & $50 \mathrm{Mg}$ \\
Anak-anak 1 - 3 tahun & $15 \mathrm{Mg}$ \\
Anak-anak 4 - 8 tahun & $25 \mathrm{Mg}$ \\
Anak-anak 9 - 13 tahun & $45 \mathrm{Mg}$ \\
Remaja 14-18 tahun (Laki-laki) & $75 \mathrm{Mg}$ \\
Remaja 14-18 tahun (Perempuan) & $65 \mathrm{Mg}$ \\
Dewasa (Pria) & $90 \mathrm{Mg}$ \\
Dewasa (Wanita) & $75 \mathrm{Mg}$ \\
Remaja hamil & $80 \mathrm{Mg}$ \\
Wanita hamil & $85 \mathrm{Mg}$ \\
Remaja menyusui & $115 \mathrm{Mg}$ \\
Wanita menyusui & $120 \mathrm{Mg}$ \\
\hline
\end{tabular}

Sumber: (Institute of Medicine, 2000)

Kebanyakan orang memperoleh asupan vitamin dari buah. Buah yang banyak mengandung vitamin C yaitu belimbing, kiwi, stroberi, dan jambu biji. Buah jeruk juga mengandung vitamin C, namun lebih rendah dari buah yang disebutkan diatas (Ellong et al., 2015).

Ravindran et al., (2004), menyatakan bahwa kayu manis mengandung vitamin $(\mathrm{A}, \mathrm{C}, \mathrm{K}, \mathrm{B} 3)$ dan mineral. Kadar vitamin C pada kayu manis sekitar 3,8 mg (FoodData Central, n.d.). Kemungkinan kadar vitamin $\mathrm{C}$ pada sari buah meningkat karena adanya penambahan kandungan vitamin $\mathrm{C}$ dari kayu manis.

Pada penurunan kadar vitamin C, Octaviani dan Rahayuni (2014) menyatakan bahwa semakin tinggi kadar gula yang ditambahkan, maka kadar vitamin $\mathrm{C}$ dalam sari buah semakin menurun. Kemudian menurut Joseph, et al. (2017), penambahan gula menyebabkan lebih banyak air yang keluar dari bahan dan air dapat melarutkan vitamin $\mathrm{C}$ sehingga vitamin $\mathrm{C}$ dari bahan berkurang. 


\section{Aktivitas Antioksidan}

Antioksidan adalah suatu zat yang dapat melindungi sel dari kerusakan yang disebabkan oleh molekul tidak stabil yang dikenal dengan radikal bebas. Antioksidan menstabilkan radikal bebas dan mencegah kerusakan yang dapat ditimbulkan oleh radikal bebas. Contoh antioksidan termasuk beta-karoten, likopen, vitamin C, E, A dan zat lainnya (Hamid et al., 2010).

Hasil yang ditunjukan pada Tabel 5 menyatakan bahwa aktivitas antioksidan tertinggi terdapat pada perlakuan K2G0 (4\% kayu manis dan
$0 \%$ gula merah) dengan nilai $\mathrm{IC}_{50} 39,08 \mathrm{ppm}$. Kemudian hasil uji anova untuk nilai $\mathrm{IC}_{50}$ terdapat pada Tabel 6, menunjukkan bahwa dari 24 sampel berbeda nyata karena nilai $\mathrm{p}<0,05$. Nilai $\mathrm{IC}_{50}$ semakin rendah menunjukkan semakin tingginya aktivitas antioksidan. Suatu senyawa dikatakan memiliki aktivitas antioksidan "sangat kuat" jika nilai $\mathrm{IC}_{50}$ kurang dari $50 \mathrm{ppm}$, aktivitas antioksidan "kuat" untuk $\mathrm{IC}_{50}$ dengan nilai 51-100 ppm, aktivitas antioksidan sedang dengan nilai $\mathrm{IC}_{50} 101$ $150 \mathrm{ppm}$, dan aktivitas antioksidan yang lemah jika nilai $\mathrm{IC}_{50}$ 151-200 ppm (Molyneux, 2004).

Tabel 5. Aktivitas Antioksidan

\begin{tabular}{cc}
\hline Perlakuan & Nilai $\mathrm{IC}_{50}(\mathrm{ppm})$ \\
\hline K1G0 & 41,04 \\
K1G1 & 41,04 \\
K1G2 & 47,41 \\
K1G3 & 53,10 \\
K2G0 & 39,08 \\
K2G1 & 40,62 \\
K2G2 & 46,81 \\
K2G3 & 49,93 \\
\hline
\end{tabular}

Tabel 6. Uji Anova Nilai IC $_{50}$

\begin{tabular}{rrrrrr}
\hline Cases & Sum of Squares & $d f$ & Mean Square & $F$ & $p$ \\
\hline Perlakuan & 553,557 & 7 & 79,080 & 190,385 & $<0,001$ \\
Residuals & 6,646 & 16 & 0,415 & & \\
\hline
\end{tabular}

Note. Type III Sum of Squares

Kulit batang kayu manis (Cinnamomum burmanii) mengandung senyawa antioksidan berupa polifenol (flavonoid, tanin) serta minyak atsiri golongan fenol (Ervina et al., 2016). Senyawa fenolik tersebut berkontribusi terhadap aktivitas antioksidan. Bandara et.al (2011) menyebutkan bahwa kayu manis memiliki kemampuan antifungi, antimikroba, antivirus, antitumor, antioksidan, penurun tekanan darah, kolesterol dan pula memiliki senyawa rendah lemak.

Penambahan gula merah yang dilakukan pada sari buah jambu biji memberikan hasil yang kurang baik karena nilai $\mathrm{IC}_{50}$ meningkat yang menandakan bahwa aktivitas antioksidan menurun. 
Andriani \& Amanto (2012), menyatakan bahwa semakin banyak gula, maka akan terjadi penurunan kadar fenol, kadar tanin dan aktivitas antioksidan yang disebabkan oleh senyawa flavonol yang mengikat molekul gula sehingga mengakibatkan pelarutan komponen polifenol terganggu.

\section{KESIMPULAN}

Kandungan vitamin $\mathrm{C}$ dan aktivitas antioksidan terbaik terdapat pada perlakuan K2G0 (4\% kayu manis dan $0 \%$ gula merah). Hal tersebut kemungkinan disebabkan oleh pemberian kayu manis pada sari buah jambu biji merah. Sedangkan pada pemberian gula merah, semakin banyak gula merah yang diberikan pada sari buah jambu biji merah, penurunan kandungan vitamin $\mathrm{C}$ dan aktivitas antioksidan semakin banyak pula.

\section{UCAPAN TERIMA KASIH}

Terima kasih kepada Institut Teknologi dan Kesehatan Bali yang telah memberikan dana Hibah Penelitian Internal. Terima kasih pula kepada Laboratorium Analisis Pangan, Fakultas Pertanian, Universitas Warmadewa yang telah memberikan penulis untuk melakukan penelitian. Tidak lupa kami ucapkan terima kasih kepada Jurnal Ilmu dan Teknologi Pangan (ITEPA), Fakultas Teknologi Pertanian, Universitas Udayana yang telah mengijinkan artikel ini untuk terbit. Semoga artikel ini bermanfaat bagi kita semua.

\section{DAFTAR PUSTAKA}

Abdurachman, A., \& Hadjib, N. (2011). Sifat Papan Partikel dari Kayu Kulit Manis (Cinnamomum burmanii BL). Jurnal
Penelitian Hasil Hutan, 29(2), 128-141. doi:https://doi.org/10.20886/jphh.2011.29.2.1 28-141

Andriani, M., Amanto, B., \& Gandes, G. (2012). Pengaruh Penambahan Gula dan Suhu Penyajian Terhadap Nilai Gisi Minuman Teh Hijau (Camellia sinensis L.). Jurnal Teknologi Hasil Pertanian, 5(1). doi:http://dx.doi.org/10.20961/jthp.v0i0.1354 2

Bandara, T., Uluwaduge, I., \& Jansz, E. R. (2012). Bioactivity of cinnamon with special emphasis on diabetes mellitus: a review. International journal of food sciences and nutrition, 63(3), 380-386. https://doi.org/10.3109/09637486.2011.6278 $\underline{49}$

Ellong, E. , Billard, C. , Adenet, S. and Rochefort, K. (2015) Polyphenols, Carotenoids, Vitamin C Content in Tropical Fruits and Vegetables and Impact of Processing Methods. Food and Nutrition Sciences, 6, 299-313. doi: 10.4236/fns.2015.63030.

Ervina, M.; Nawu, Y. E.; Esar, S. Y. 2016. Comparison of In Vitro Antioxidant Activity of Infusion, Extract and Fractions of Indonesian Cinnamon (Cinnamomum Burmannii) Bark. International Food Research Journal 23(3): 1346-1350.

Ferry, Y., \& Pakuwon, J. R. (2013). Development Prospects of Cinnamon Plant. 1(1), 10.

Hamid, A.A., Aiyelaagbe, O.O., Usman, L.A., Ameen, O.M. and Lawal, A. (2010) Antioxidants: Its Medicinal and Pharmacological Applications. African Journal of Pure and Applied Chemistry, 4, 142-151.

Harefa, N., Feronika, N., Kana, A. D., Hutagalung, R., Chaterine, D., \& Bela, Y. (2020). Analisis Kandungan Vitamin C Bahan Makanan dan Minuman dengan Metode Iodimetri. Science Education and Application Journal, 2(1), 35. https://doi.org/10.30736/seaj.v2i1.194

Institute of Medicine. (2000). Dietary Reference Intakes for Vitamin C, Vitamin E, Selenium, and Carotenoids. The National Academies Press. https://doi.org/10.17226/9810

Joseph, GS., Lana, L. \& Maria, FS. (2017). Pengaruh Sukrosa terhadap Karakteristik Fisikokimia dan Sensoris Manisan Kering Paprika Merah (Capsicum Annuum Var Grossum). Cocos, 1(7), 1-12.

Kristianingrum. 2009. Analisis Nutrisi dalam Gula Semut. Jurusan Pendidikan Kimia 
Fakultas Matematika dan Ilmu Pengetahuan Alam Universitas Negri Yogyakarta.

Li, Y., \& Schellhorn, H. E. (2007). New developments and novel therapeutic perspectives for vitamin C. The Journal of nutrition, 137(10), 2171-2184. https://doi.org/10.1093/jn/137.10.2171

Molyneux, P. (2004) The Use of Stable Free Radical Diphenylpicrylhydrazyl (DPPH) for Estimating Antioxidant Activity. Songklanakarin Journal of Science and Technology, 26, 211-219.

Morton, J. (1987) Roselle. In: Fruits of Warm Climate, Julia F. Morton, Miami, FL, 281286.

http://www.hort.purdue.edu/newcrop/morton ne/roselle.html

Office of Dietary Supplements-Vitamin C. (n.d.). Retrieved August 16, 2022, from https://ods.od.nih.gov/factsheets/VitaminCConsumer/
Octaviani, L. F., \& Rahayuni, A. (2014). Pengaruh Berbagai Konsentrasi Gula terhadap Aktivitas Antioksidan dan Tingkat Penerimaan Sari Buah Buni (Antidesma bunius). Journal of Nutrition College, 3(4), 958-965. https://doi.org/10.14710/jnc.v3i4.6916

Ravindran, P. N., Nirmal Babu, K., \& Shylaja, M. (Eds.). (2004). Cinnamon and cassia: The genus Cinnamomum. CRC Press.

FoodData Central. (n.d.). Retrieved August 16, 2021, from https://fdc.nal.usda.gov/fdcapp.html\#/food-details/171320/nutrients

Uzzaman, S., Akanda, K. M., Mehjabin, S., \& Parvez, G. M. M. (2018). A short review on a Nutritional Fruit: Guava. Open Access, 1(1), 9.

Wiralis. 2009. "Pengaruh Pemberian Jus Jambu Biji (Psidium guajava L) Terhadap Kadar Ion Nitrit Dan Gambaran Histopatologik Panus Sendi Adjuvant Induced Arthritis Tikus Wistar". Media Medika Indonesiana. 43 (4). 